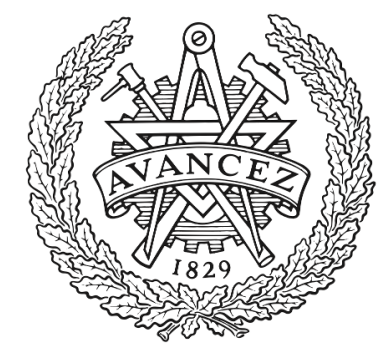

\title{
CHALMERS
}

UNIVERSITY OF TECHNOLOGY

\section{Design of Wideband Slot Array Antenna by Groove Gap Waveguide in Millimeter Waves}

Downloaded from: https://research.chalmers.se, 2023-04-26 03:04 UTC

Citation for the original published paper (version of record):

Liu, J., Uz Zaman, A., Yang, J. (2018). Design of Wideband Slot Array Antenna by Groove Gap Waveguide in Millimeter Waves. 2018 IEEE-APS Topical Conference on Antennas and Propagation in Wireless Communications (APWC). http://dx.doi.org/10.1109/APWC.2018.8503800

N.B. When citing this work, cite the original published paper. 


\title{
Design of Wideband Slot Array Antenna by Groove Gap Waveguide in Millimeter Waves
}

\author{
Jinlin Liu ${ }^{1}$, Ashraf Uz Zaman ${ }^{1}$ and Jian Yang ${ }^{1}$ \\ ${ }^{1}$ Department of Electrical Engineering, Chalmers University of Technology, Gothenburg, Sweden. \\ jinlin.liu@chalmers.se
}

\begin{abstract}
The newly introduced gap waveguide technology offers non-contact waveguide configurations so that the good electrical contact between different metallic layers can be avoided. Thereby, the gap waveguide structures are relatively simple to manufacture, especially at millimeter and sub-millimeter wave frequencies. This work systematically presents a high-efficiency corporate-fed slot array antenna based on groove gap waveguide in the millimeter waves. A cavity-backed slot sub-array is firstly designed in a groove gap waveguide cavity. The cavity is fed through a coupling hole from groove gap waveguide distribution network at the bottom layer. The sub-array is numerically optimized in an infinite array environment. Low side lobes are obtained in the both $\mathrm{E}$ - and $\mathrm{H}$-planes by diagonal placement of the radiation slot rotating by 45 degrees. Furthermore, the radiation narrow slot pair is adopted so that the good cross polarization is achieved. The fabricated antenna depicts more than $25 \%$ bandwidth with input reflection coefficient better than $-8 \mathrm{~dB}$ and the aperture efficiency higher than $60 \%$ with around $25 \mathrm{dBi}$ realized gain between 70 and $90 \mathrm{GHz}$. The measured cross polarization level is below $-27 \mathrm{~dB}$, which satisfies the ETSI standard.
\end{abstract}

Index Terms-groove gap waveguide, wide band slot array antenna.

\section{INTRODUCTION}

Recently, the saturation of spectrum at microwave frequencies causes the consideration of higher frequency bands. Especially, the millimeter wave range between $30 \mathrm{GHz}$ and $300 \mathrm{GHz}$ has been paid lots of attentions [1]-[2]. Furthermore, the usage of the millimeter wave frequencies has the advantage of allowing for larger bandwidths, and thereby, achieving higher data transfer rates. In such frequency ranges, traditional hollow waveguide and microstrip lines have met up with difficulties to design antennas and passive components.Indeed, hollow waveguide are normally manufactured in two parts and then joined together. In microwave frequency band, it is still convenient to fabricate hollow waveguide because its geometrical dimensions are large. However, its fabrication becomes a big problem because its dimensions are very small in millimeter waves. Moreover, it suffers from problems of irregular rectangular shape and poor electrical contacts. Diffusion bonding and vacuum welding are probably two manufacture technologies for hollow waveguide in millimeter waves [3]. Nevertheless, its fabrication cost is relatively high. On the other hand, microstrip lines or covered microstrip lines are able to integrate the active components, but still present high dielectric losses in millimeter waves. Thereby, new technologies in millimeter waves are still demanded.

Substrate integrated waveguide (SIW) is a appropriate candidate in millimeter waves. Nevertheless, it exhibits undesired dielectric losses in the substrate at increasing frequencies. As is well known, the loss tangent value of substrate increases versus the frequency. Thereby, the dielectric loss in SIW is unacceptable above $60 \mathrm{GHz}$ so that the antenna efficiency is affected [4]-[5]. In such a situation, there is still need to find new technological solutions for waveguides that have low losses and are cheap to manufacture. The recently introduced gap waveguide technology [6] constitutes a new type of guiding structure that shows lot of potential to overcome the issues of conventional technologies, and become a suitable approach at millimeter wave frequencies. First of all, the gap waveguide shows low loss compared with microstrip, covered microstrip and SIW. Secondly, unlike the conventional manufacture of hollow waveguide, the gap waveguide structure is very flexible to be manufacture. Most importantly, the electrical contact between the building blocks is not needed in this new guiding structure so that expensive fabrication technologies, such as vacuum welding and diffusion bonding, can be avoided in millimeter waves. Until now four different variety of gap technology, ridge gap waveguide, groove gap waveguide, microstrip-gap waveguide, and inverted microstrip-

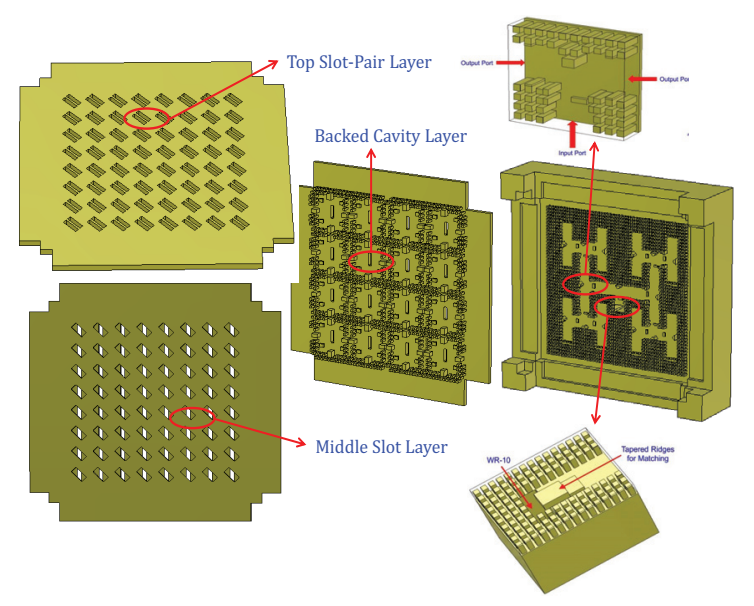

Fig. 1. Configuration of the proposed corporate-feed slot array antenna based on groove gap waveguide. 


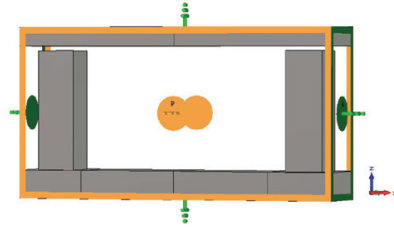

(a)

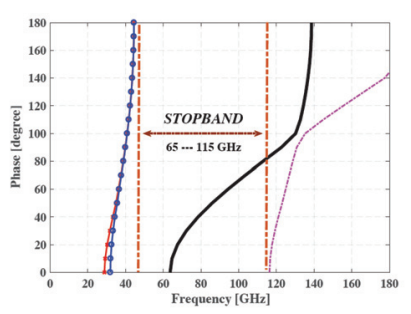

(b)
Fig. 2. (a) A groove gap waveguide unit cell for determination of dispersion diagram. (b) The corresponding dispersion diagram.

ridge gap waveguide have been already investigated. In [7]-[9] slot array antennas based on gap waveguide technology have been finished. They are able to achieve characteristics of highgain and high-efficiency because of low loss property. In [10][11] filter and duplexer have been developed. In addition, gap waveguide is also able to be applied for microwave circuits packaging [12].

In this work, we Initially introduce a $45^{\circ}$ linearly polarized corporate-feed groove gap waveguide slot array antenna covering 71.5 to $90 \mathrm{GHz}$. As depicted in Fig. 1, the whole slot array antenna consists of the distribution feeding networks, the backed cavity layer, the middle slot layer and the top radiation slot layer. The feeding part is composed of equallysplit H-plane T-junctions and a vertical transition from WR10 standard hollow waveguide from its back. In order to satisfy the radiation pattern of ETSI standard, the radiation slots in this work have been $45^{\circ}$ rotated [13]-[14]. Given the

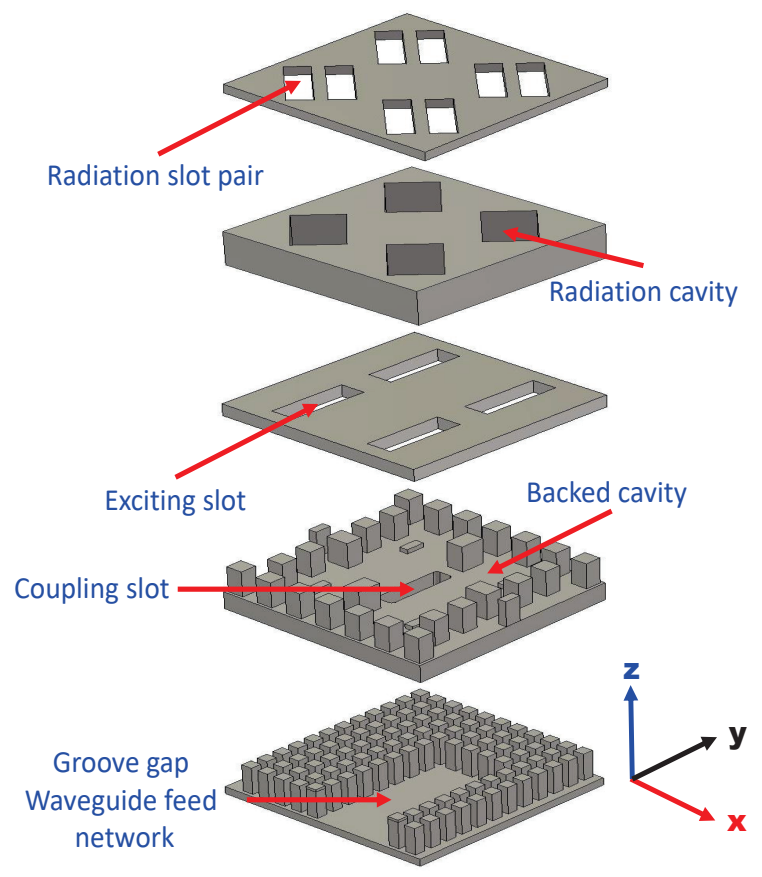

Fig. 3. Model for the analysis of the $2 \times 2$-element sub-array. rising of the cross polarization level caused by $45^{\circ}$ degree rotation, a narrow-slot pair configuration on the top is designed to suppress the cross-polarization. The proposed antenna has been fabricated by computerized numerical control (CNC) milling machine. The measured reflection coefficient and farfield radiation patterns are discussed in the end.

\section{DESIGN OF SUB-ARRAY}

The pin dimensions of bed of nails at both distribution networks and backed cavities should be chosen correctly to achieve a parallel plate stopband which covers as much as the operating frequency. As depicted in Fig. 2 (a), the design unit cell of proposed groove gap waveguide is built with PEC, periodic and PEC boundary conditions in $\mathrm{x}-, \mathrm{y}$ - and $\mathrm{z}$-axis in CST Microwave Studio, respectively. Correspondingly, the dispersion diagram of the structure is shown in Fig. 2(b), which is obtained by utilizing the eigenmode solver in CST

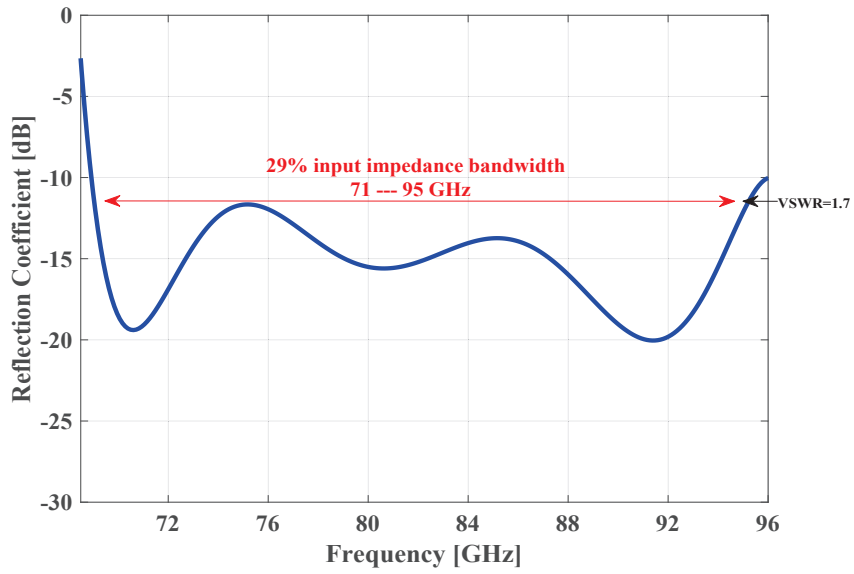

Fig. 4. The reflection coefficient of the sub-array.

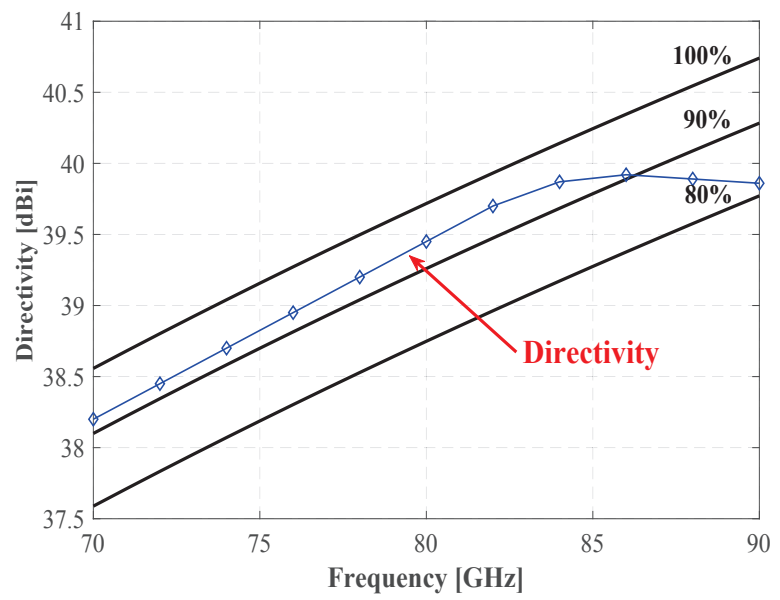

Fig. 5. The simulated directivity of the $32 \times 32$ slot array according to the periodic boundary condition. 


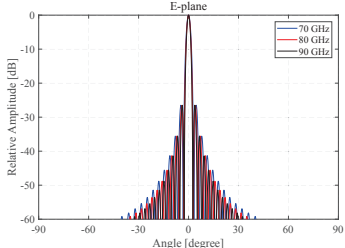

(a)

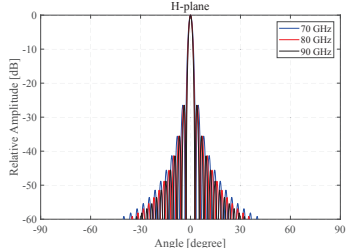

(b)
Fig. 6. Normalized radiation patterns of an array with $32 \times 32$ slot aperture dimension in (a). E-plane and (b). H-plane. Infinite array approach.

Microwave Studio. The obtained stopband is from 65 to 115 GHz. The proposed $2 \times 2$ sub-array is illustrated in Fig. 3. The sub-array consists of four layers - the top pair radiation layer, the middle slot layer, the backed cavity layer and the bottom distribution feed networks layer. An air-filled cavity formed by pins, feeds four radiating slots with spacing smaller than $3.1 \mathrm{~mm}$, which is equal to one wavelength on the top layer. A groove gap waveguide excites the cavity via a coupling slot on the bottom layer. There is a small gap between each layers and thereby no electrical contact between the different layers. This is a manufacturing advantage of this technology. The designed sub-array has $6 \times 6 \mathrm{~mm}^{2}$ dimensions. The subarray is optimized in the infinite array environment by using CST Microwave Studio where the mutual coupling between sub-arrays are automatically included. The simulated reflection coefficient of the sub-array is illustrated in Fig. 4. The subarray bandwidth is $29 \%(71-95 \mathrm{GHz})$ with the VSWR better than 1.7. The directivity versus frequency of an array with the same aperture size is shown in Fig. 5. The blue line in the graph shows the maximum available directivity between $100 \%$ and $80 \%$ aperture efficiency, which clearly shows that the designed sub-array has high aperture efficiency. In Fig. 6, the E- and H-plane far field patterns of an array with $32 \times 32$ slots over its aperture are illustrated for different frequencies.
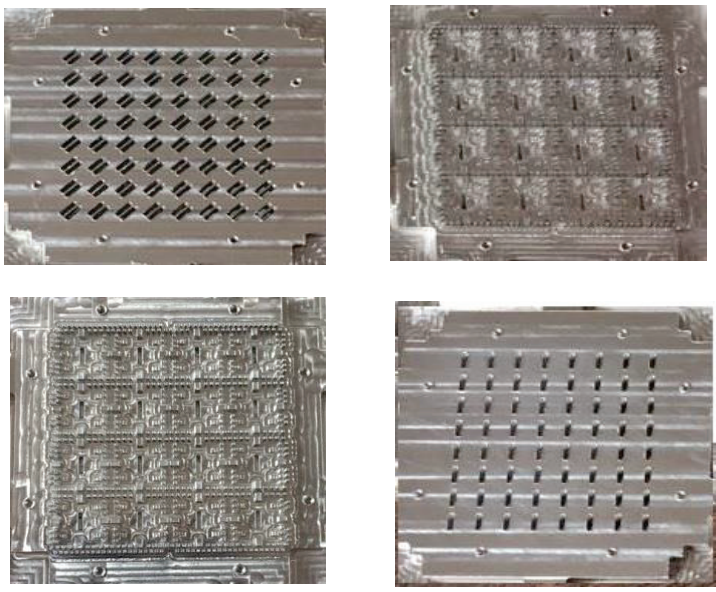

Fig. 7. Picture of manufactured antenna in this work.

\section{Simulation and Measurement for the $8 \times 8$ SLOT ARRAY}

The fabricated $8 \times 8$ slot array antenna is illustrated in Fig. 8 . The prototype is manufactured by Computerized Numerical Control (CNC) technology. The fabricated machine is Fanuc $\alpha$ D14B15 with fabrication tolerance $2.5 \mu \mathrm{m}$, and this is good enough to fabricate our array antenna. The dimensions of effective aperture are $24 \times 24 \mathrm{~mm}^{2}$ and it was fabricated by aluminium (with electric conductivity $3.6 \times 10^{7} \mathrm{~S} / \mathrm{m}$ ). The entire structure is simulated in CST Microwave Studio. The simulated reflection coefficient of complete antenna is below $-10 \mathrm{~dB}$ from 70 to $90 \mathrm{GHz}$, as shown in Fig. 9. However, the measured reflection coefficient is a bit higher than simulated one because of the tolerances of manufacturing and assembling tolerances. Still, it covers 71.5 to $90 \mathrm{GHz}$ with the VSWR better than 2.4. The simulated far-field radiation patterns of proposed antenna at 70, 80 and $90 \mathrm{GHz}$ in both E- and $\mathrm{H}-$ planes are depicted in Fig. 9. Low sidelobe characteristics are obtained over the bandwidth investigated here. No grating lobe is observed. The simulated first sidelobe levels are less than $-26 \mathrm{~dB}$. The measured frequency characteristics of the gain and the cross polarization are shown in Fig. 10. The gain and the cross polarization are measured by $\mathrm{V}$ - and $\mathrm{W}$-band far-field measurement systems for $70-75 \mathrm{GHz}$ and $75-90$

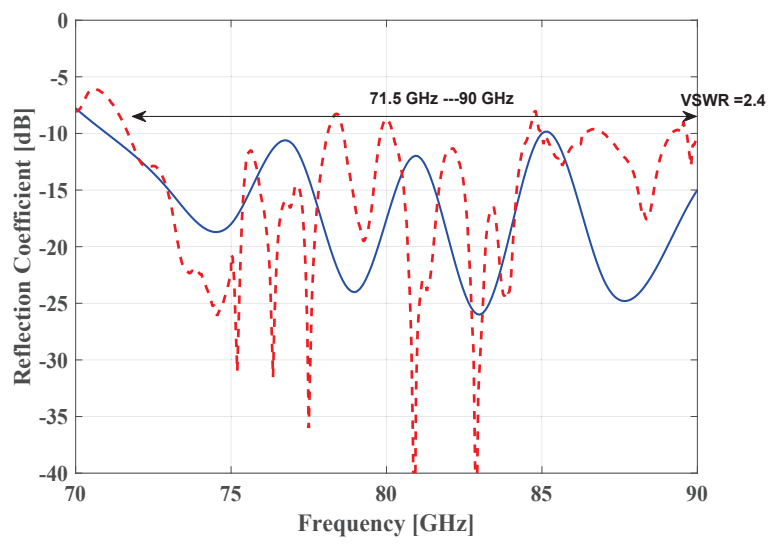

Fig. 8. The simulated and the measured reflection coefficients of proposed antenna. The blue curve indicates the simulated reflection coefficient, and the red line depicts the measured one. (a)

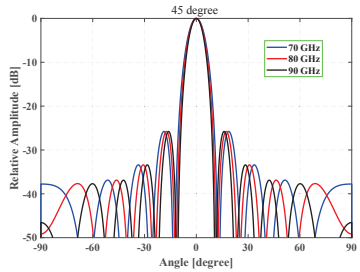

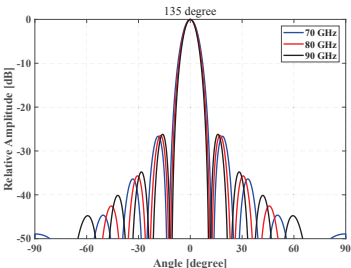

(b)
Fig. 9. The simulated far-field radiation patterns of proposed antenna. (a) E-plane and (b) H-plane. 


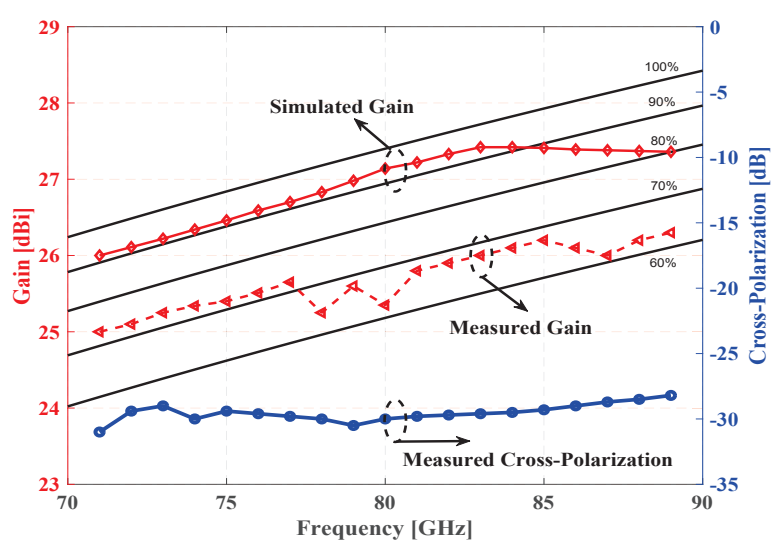

Fig. 10. The simulated and measured gains of the proposed array antenna. The measured one shows the antenna efficiency is higher than $60 \%$. The measured cross-polarization is better than $-27 \mathrm{~dB}$, which fulfills the ETSI standard.

$\mathrm{GHz}$, respectively. In the $71-89 \mathrm{GHz}$ band, the gain variation is $25-26.2 \mathrm{dBi}$. The bandwidth for a gain of more than 25 $\mathrm{dBi}$ and the antenna efficiency of more than $60 \%$ is greatly improved. The cross polarization is suppressed below $-27 \mathrm{~dB}$ over the full bandwidth. In [14] the the cross polarization level are very well pressed under $-30 \mathrm{~dB}$, but this work has not achieved the outcome. The main reason for the problem is that the assembly of the four layers array antenna always has small geometrical errors, which makes the drop of gain and the rise of the cross-polarization and the reflection coefficient.

\section{CONCLUSION}

In this work, we present a 45 degree $8 \times 8$ cavity-backed slot array antenna based on groove gap waveguide for highgain $80 \mathrm{GHz}$. The proposed antenna consists of four layers, i.e. 45 degree radiation slot layer, middle coupling slot layer, backed cavity layer and feeding network layers without need of electrical contact between layers. This presents manufacturing advantages in particular at millimeter wave. The array antenna can be directly connected with standard WR-10 interface. The measured gain is higher than $25 \mathrm{dBi}$ from 71 to $90 \mathrm{GHz}$, correspondingly the antenna efficiency larger than $60 \%$.

\section{ACKNOWLEDGEMENT}

The authors would like to thanks Dr. Kuikui Fan at Southeast University in Nanjing for the measurement of the reflection coefficient and Shanghai Academy of Spaceflight Technology for the measurement of the gain and cross polarization level.

\section{REFERENCES}

[1] P. Smulders, "Exploring the 60-GHz band for local wireless multimedia access: Prospects and future directions," IEEE Commun. Mag., vol. 40, no. 1, pp. 40-147, Jan. 2002.

[2] T. S. Rappaport, J. N. Murdck, and F. Gutierrez, "State of the art in 60$\mathrm{GHz}$ integrated circuits and systems for wireless communications," Proc. IEEE, vol. 99, no. 8, pp. 1390-1436, Aug. 2011.

[3] Y. Miura, J. Hirokawa, M. Ando, Y. Shibuya and G. Yoshida, "Doublelayer full-corporate-feed hollow-waveguide slot array antenna in the 60 GHz band," IEEE Trans. Antennas Propag., vol. 59, no. 8, pp. 2844 2851, Aug. 2011.

[4] Y. Li and K.-M. Luk, "Low-cost high-gain and broadband substrate integrated-waveguide-fed patch antenna array for $60-\mathrm{GHz}$ band," IEEE Trans. Antennas Propag., vol. 62, no. 11, pp. 5531-5538, Nov. 2014.

[5] Y. Li and K.-M. Luk, "60-GHz substrate integrated waveguide fed cavitybacked aperture-coupled microstrip patch antenna arrays," IEEE Trans. Antennas Propag., vol. 63, no. 3, pp. 1075-1085, Mar. 2015.

[6] P.-S. Kildal, "Three metamaterial-based gap waveguides between paralle metal plates for $\mathrm{mm} / \mathrm{submm}$ waves," in proceeding of $3 \mathrm{rd}$ European Conference on Antennas and Propagation, EuCAP 2009, pp. 28-32.

[7] A. Vosoogh, P.-S. Kildal and Vessen Vassilev, "Wideband and highgain corporate-fed gap waveguide slot array antenna with ETSI Class II radiation pattern in V-Band," IEEE Trans. Antennas Propag., vol. 65, no. 4, pp. 1823 - 1831, April, 2017.

[8] J. L. Liu, A. Vosoogh, A. U. Zaman and J. Yang, "Design and fabrication of a high gain $60-\mathrm{GHz}$ cavity-backed slot antenna array fed by inverted microstrip gap waveguide," IEEE Trans. Antennas Propag., vol. 65, no. 4, pp. 2117 - 2122, April, 2017.

[9] J. L. Liu, A. Vosoogh, A. Uz Zaman and P.-S. Kildal, "Design of $8 \times 8$ slot array antenna based on inverted microstrip gap waveguide," Antennas and Propagation (ISAP), 2016 International Symposium on, 24-28, October, 2016.

[10] E. Rajo-Iglesias, P. S. Kildal, A. U. Zaman, and A. Kishk, "Bed of springs for packaging of microstrip circuits in the microwave frequency range," IEEE Trans. Compon. Packag. Manuf. Technol., vol. 2, no. 7, pp. 1623 - 1628, July, 2012.

[11] A. U. Zaman, P.-S. Kildal and A. A. Kishk, "Narrow-Band microwave filter using High-Q groove gap waveguide resonators with manufacturing flexibility and no sidewalls," IEEE Trans. Compon. Packag. Manuf. Technol., vol. 2, no. 11, pp. 1882 - 1889, Nov. 2012.

[12] A. U. Zaman, M. Alexanderson, T. Vukusic and P.-S. Kildal, "Gap waveguide PMC packaging for improved isolation of circuit components in high-frequency microwave modules," IEEE Trans. Compon. Packag. Manuf. Technol., vol. 4, no. 1, pp. 16 - 25, Jan. 2014.

[13] T. Tomura, Y. Miura, M. Zhang, J. Hirokawa, and M. Ando, A 45 degree linearly polarized hollow-waveguide corporate-feed slot array antenna in the $60-\mathrm{GHz}$ band, IEEE Trans. Antennas Propag., vol. 60, no. 8, pp. 36403646, Aug. 2012.

[14] T. Tomura, Y. Miura, M. Zhang, J. Hirokawa, and M. Ando, A 45 Linearly Polarized Hollow-Waveguide $16 \times 16$-Slot Array Antenna Covering 71-86 GHz Band, IEEE Trans. Antennas Propag., vol. 62, no. 10, pp. 50615067, Aug. 2014 